\title{
Clinical response and pharmacokinetics of bendamustine as a component of salvage $R-B(O) A D$ therapy for the treatment of primary central nervous system lymphoma (PCNSL)
}

Therasa Kim ${ }^{1}$, He Yun Choi ${ }^{2}$, Hyun-Seo Lee ${ }^{2}$, Sung-Hoon Jung ${ }^{3}$, Jae-Sook Ahn ${ }^{3}$, Hyeoung-Joon Kim³, Je-Jung Lee ${ }^{2,3}$, Hee-Doo Yoo ${ }^{4^{*}}$ and Deok-Hwan Yang ${ }^{2,3^{*}}$

\begin{abstract}
Background: A relatively high proportion of patients diagnosed with primary CNS lymphoma will experience recurrent disease, yet therapy options are limited in salvage therapy. This is the first study to evaluate a bendamustine-based combination regimen for the treatment of relapsed/refractory PCNSL and to characterize bendamustine pharmacokinetics in the human CSF.

Methods: Patients received bendamustine $75 \mathrm{mg} / \mathrm{m}^{2}$ for two days as part of $\mathrm{R}-\mathrm{B}(\mathrm{O}) \mathrm{AD}$ administered intravenously every 4 weeks for up to 4 cycles. Response and adverse events of the regimen were assessed. A sparse sampling strategy and population based modeling approach was utilized for evaluation of plasma and CSF levels of bendamustine.

Results: Ten patients were enrolled into study of whom $70 \%$ were of refractory disease and with high IELSG prognostic risk scores. The ORR of R-BOAD was $50 \%(95 \% \mathrm{Cl}, 0.24$ to 0.76$)$ with one patient achieving CR and four PR. Primary toxicity of the regimen was reversible myelosuppression, mostly grade 3 or 4 neutropenia. The $C_{\max }$ mean for plasma and CSF were $2669 \mathrm{ng} / \mathrm{mL}$ and $0.397 \mathrm{ng} / \mathrm{mL}$, respectively, and patients with response at deep tumor sites displayed higher trends in peak exposure. Pharmacokinetic data was best described by a fourcompartment model with first-order elimination of drug from central plasma and CSF compartments.
\end{abstract}

Conclusions: R-BOAD is an effective salvage option for PCNSL, but with significant hematologic toxicity. Bendamustine CSF levels are minimal; however correspond to plasma exposure and response.

Trial registration: ClinicalTrials.gov NCT03392714; retrospectively registered January 8, 2018.

Keywords: Bendamustine, CSF, Pharmacokinetics, Primary CNS lymphoma, Salvage therapy

\footnotetext{
* Correspondence: yooheedoo@gmail.com; drydh1685@hotmail.com

${ }^{4}$ Department of Biostatistics and Bioinformatics, Pharma Partnering Inc., 74

Olympicro, Songpagu, Seoul 05556, Republic of Korea

${ }^{2}$ Research Center for Cancer Immunotherapy, Chonnam National University Hwasun Hospital, 322 Seoyangro, Hwasun, Jeollanamdo 58128, Republic of Korea

Full list of author information is available at the end of the article
}

(c) The Author(s). 2018 Open Access This article is distributed under the terms of the Creative Commons Attribution 4.0 International License (http://creativecommons.org/licenses/by/4.0/), which permits unrestricted use, distribution, and reproduction in any medium, provided you give appropriate credit to the original author(s) and the source, provide a link to the Creative Commons license, and indicate if changes were made. The Creative Commons Public Domain Dedication waiver (http://creativecommons.org/publicdomain/zero/1.0/) applies to the data made available in this article, unless otherwise stated. 


\section{Background}

Primary central nervous system lymphoma (PCNSL) is a rare form of CNS malignancy representing 2-4\% of all primary CNS tumors and is of mainly diffuse large B-cell lymphoma (DLBCL) origin $[1,2]$. Despite high sensitivity to radiation and chemotherapy, one third of the patient population is refractory to first-line therapy and up to half of the responders will relapse after remission from initial treatment, mostly within the CNS [3, 4]. Salvage therapy will be required for a significant percentage of the PCNSL population, yet there is no current standard of therapy in the relapsed/refractory $(R / R)$ setting due to the lack of data from randomized clinical trials. High dose methotrexate (HD-MTX) re-challenge in patients with previously MTX responsive disease is a feasible option reporting high response rates, $[5,6]$ and numerous single or combination therapy regimens have been examined in small prospective studies with overall response rates ranging from 30 to $55 \%$ [7-9].

Bendamustine is a bifunctional alkylating agent possessing both alkylator and antimetabolite properties from a mechlorethamine moiety and benzimidazole ring, respectively. [10] Recently, several case reports have suggested that bendamustine has modest clinical activity as single agent therapy against relapsed PCNSL with reasonable tolerability $[11,12]$. However, the effect of this agent as part of combination salvage therapy in patients with PCNSL has not been established. The purine analog-like properties of bendamustine are thought to augment the apoptotic effects of pyrimidine analogs such as cytarabine, and synergy against DLBCL cell lines has been shown to be greatest when administered sequentially [13] where therapeutic impact has been validated in several trials involving mantle cell lymphoma patients $[14,15]$. Similarly, vincristine has documented efficacy against lymphoid malignancies when used in combination with bendamustine in both in vitro and clinical studies $[16,17]$.

Although the role of rituximab in PCNSL has some controversy, a recent meta-analysis has shown that additional use of the CD20-targeted monoclonal antibody in initial therapy correlates with higher response rates [18], and other studies in the salvage setting have reported positive outcomes, albeit a more modest response in prospectively conducted trials $[19,20]$. Based on the demonstrated activity and proposed additive mechanisms of these chemotherapeutic agents, we investigated the bendamustine-based combination regimen $\mathrm{R}-\mathrm{B}(\mathrm{O}) \mathrm{AD}$ in patients with refractory or relapsed primary CNS lymphoma. Evidence from previous preclinical tissue distribution studies and single agent intravenous drug therapy trials in CNS malignancies suggests that bendamustine penetrates brain and tumor tissue [12, 21-23], and while cerebrospinal fluid (CSF) drug concentrations are commonly used as a surrogate marker of CNS delivery, there are no clinical data available on the pharmacokinetics (PK) of bendamustine in the CSF. In light of rarity of the disease and difficulties in obtaining extensive data samples, a nonlinear mixed-effects modeling approach was considered appropriate for drug evaluation. Thus, we evaluated the PK of plasma and CSF drug levels through a population based model approach in a R/R PCNSL cohort with the goals to define the currently unknown PK profile of bendamustine in the CSF and to further characterize the relationship between plasma and CSF drug levels, and the influence of exposure on response to therapy.

\section{Methods \\ Study eligibility}

Eligible patients were $\geq 19$ years of age with PCNSL of DLBCL origin diagnosed by CNS lesion tissue biopsy, and in relapse or refractory to frontline chemotherapy or radiation, with confirmed evidence of disease progression by contrast enhanced magnetic resonance imaging (MRI). Additional requirements were Eastern Cooperative Oncology Group (ECOG) performance status $0-2$ and adequate hematologic and organ function including absolute neutrophil count $(\mathrm{ANC}) \geq 1000 / \mathrm{uL}$, platelets $\geq 100,000 / \mathrm{uL}$, total bilirubin $\leq 1.5 \mathrm{x}$ upper limit of normal (ULN), transaminases $\leq 3 \times$ ULN, and serum creatinine $\leq 2.0 \times$ ULN. Patients with uncontrolled infection, therapy with myelosuppressive chemotherapy or biologic therapy $<21$ days prior to registration, persistent toxicities $\geq$ grade 3 from prior chemotherapy, history of thromboembolic episodes $\leq 3$ months prior to registration, active hepatitis $\mathrm{B}$ or $\mathrm{C}$ with uncontrolled disease, or with active other malignancy requiring treatment that would interfere with assessments of lymphoma response to protocol treatment were excluded from enrollment.

\section{Study design and treatment}

This was a prospective, open-label, pilot study investigating the safety and efficacy of the bendamustine-based combination regimen $\mathrm{R}-\mathrm{B}(\mathrm{O}) \mathrm{AD}$, designed to define CSF and plasma $\mathrm{PK}$ profiles of bendamustine in $\mathrm{R} / \mathrm{R}$ patients. All patients received either R-BOAD or R-BAD intravenously (rituximab $375 \mathrm{mg} / \mathrm{m}^{2}$ on day 1 ; vincristine $1.4 \mathrm{mg} / \mathrm{m}^{2}$ on day 1 , omitted in patients $\geq 70$ years of age due to risk of neurotoxicity; bendamustine $75 \mathrm{mg} / \mathrm{m}^{2}$ over $1 \mathrm{~h}$ on days 2 and 3; cytarabine $1000 \mathrm{mg} / \mathrm{m}^{2}$ over $3 \mathrm{~h}$ on days 2-4; dexamethasone $20 \mathrm{mg}$ on days $1-4$ ), every 4 weeks up to 4 cycles. Initial reduction of bendamustine or cytarabine dosage was allowed if deemed necessary by the physician due to elderly age or poor performance status. Subcutaneous granulocyte colony-stimulating factor support was administered post chemotherapy on starting day 7 of the cycle in all patients until $\mathrm{ANC} \geq 500 / \mathrm{uL}$. Treatment cycles were delayed until hematologic parameters allowed for the next cycle of therapy (i.e. $\mathrm{ANC} \geq 1000 / \mathrm{uL}$, platelets $\geq 75,000 / \mathrm{uL}$ ). If a cycle was postponed $>1$ week due to hematologic toxicity 
bendamustine and cytarabine doses were reduced by was $25 \%$ in subsequent cycles. For vincristine, drug dose was reduced by $50 \%$ in the case of moderate neurotoxicity (grade 2 ), and if severe (grade 3 or 4) was discontinued for all subsequent cycles.

\section{Efficacy and safety measurements}

Baseline assessments included physical and neurological examination, laboratory studies, ocular slit lamp and CSF examination, and contrast enhanced cranial MRI. Once enrolled into study, response was assessed after every two cycles of therapy or at any time point where progression was suspected. Evaluation of response to treatment was based on criteria defined by Abrey et al. [24]. Patients who did not respond to the first two cycles of therapy were discontinued from study. The efficacy of the combination regimen was determined by ORR, defined as patients with complete (CR) or partial response (PR). Two-sided 95\% confidence intervals (CIs) are given for efficacy endpoint ORR, using the Wilson method for small sample size [25]. After completion of study treatment, patients with PR or CR were reassessed every three months. Safety was assessed after each treatment cycle by documentation of adverse events based on the NCI Common Terminology Criteria (version 4.0) through physical examination and clinical laboratory results.

\section{Pharmacokinetic assessments}

Utilizing sparse sampling strategies, plasma and CSF samples for PK analyses were acquired in pairs on the first day of bendamustine administration (day 2 of combination regimen), one pair per cycle per patient, with a cumulative target collection of three observations per time point. Sampling time points $(0 \mathrm{~min}, 30 \mathrm{~min}, 1 \mathrm{~h}$, $3 \mathrm{~h}$, and $8 \mathrm{~h}$ post completion of bendamustine infusion) were selected based on previously published plasma pharmacokinetic studies showing near complete elimination of drug within $8 \mathrm{~h}$ of infusion completion [26, 27]. Additional time points were investigated if deemed necessary to clarify plasma and CSF exposure profiles of bendamustine, but each patient was not to exceed three sampling time points during the entire course of therapy. At designated time points $5 \mathrm{~mL}$ of whole blood and $2 \mathrm{~mL}$ of CSF by lumbar puncture were drawn into evacuated EDTA and clear tubes, respectively, and immediately placed on ice. Within $1 \mathrm{~h}$, blood samples were centrifuged at $1500 \mathrm{rpm}$ for $10 \mathrm{~min}$ at $4{ }^{\circ} \mathrm{C}$, supernatant withdrawn and transferred into $100 \mathrm{uL}$ aliquots. Aliquots of plasma and CSF samples were stored at $-70{ }^{\circ} \mathrm{C}$ until quantification. Bendamustine drug concentrations were determined by validated liquid chromatography/ tandem mass spectrometry (LC-MS/MS) methodology with modifications, and a lower limit of quantification (LLOQ) of $0.05 \mathrm{ng} / \mathrm{mL}$ for CSF and $5 \mathrm{ng} / \mathrm{mL}$ for plasma [28]. The inter-day coefficients of variation for the assay of bendamustine concentrations were $\leq 3.0 \%$ and $\leq 9.4 \%$ for plasma and CSF, respectively.

\section{CSF exposure estimates and PK model}

CSF exposure was estimated as $\mathrm{C}_{\max , \mathrm{CSF}} / \mathrm{C}_{\text {max,plasma }}$ and $\mathrm{AUC}_{\mathrm{CSF}} / \mathrm{AUC}_{\text {plasma }}$ ratios. Non-compartmental methods were used to calculate the area under the concentrationtime curve $\left(\mathrm{AUC}_{0 \text {-inf }}\right)$ in WinNonlin, version 5.2 (Pharsight, St. Louis, MO, USA). The relationship between drug levels and tumor location, and interim responder status (i.e. response after two cycles of treatment or first suspected progression) was assessed by classifying patients according to observed maximum plasma and CSF concentrations, and the involvement of deep structures.

Population PK analyses were performed with NONMEM software, version 7.3 (ICON Development Solutions, Ellicott City, MD, USA) using the first-order conditional estimation method (FOCE) and ADVAN6 routine. Processing of NONMEM output and generation of plots were conducted using Xpose 4.5.3 and Sigma plot 12.0 (SYSTAT, Salano, California, USA). Plasma concentration of bendamustine was best described by a two-compartment model, parameterized for central $\left(\mathrm{V}_{1}\right)$ and peripheral $\left(\mathrm{V}_{2}\right)$ compartment volumes of distribution with inter-compartmental $\left(\mathrm{Q}_{1}\right)$ and elimination clearance (CL). For addition of the CSF compartment, a biophase reservoir was applied between the central plasma and CSF compartment. The structural model for CSF concentration data was parameterized for biophase $\left(\mathrm{V}_{3}\right)$ and $\operatorname{CSF}\left(\mathrm{V}_{4}\right)$ compartment volumes of distribution with CSF elimination clearance $\left(\mathrm{CL}_{\mathrm{csf}}\right)$ and inter-compartmental clearances $\mathrm{Q}_{2}$ and $\mathrm{Q}_{3}$. Inter-individual variability (IIV) was modeled with an exponential error model and residual variability (RV) was assessed using a proportional error model.

The most appropriate pharmacostatistical model was selected on the basis of goodness-of-fit plots, precision of estimates, and the likelihood ratio test using NONMEM generated objective function values (OFV). Goodness-of-fit plots included observed and predicted individual profiles, population predicted estimates, and conditional weighted residuals [29]. Precision of the population estimates was evaluated on the basis of relative standard errors (RSE, \%) and inter-individual variability was estimated in terms of the coefficient of variance $(\mathrm{CV}, \%)$. The accuracy and robustness of the final population model was evaluated using a non-parametric bootstrap analysis. Replication sets of the original data were generated $(N=1000)$ to which the final population model was re-fit and stability of the model was evaluated by comparing final model parameter estimates to the median and $90 \%$ CIs of the bootstrap replicates.

\section{Results}

Patient characteristics and treatment

Between January 2016 and March 2017, ten patients were enrolled into study at a single center in South 
Korea. All subjects had CNS lymphoma of DLBC origin and a majority of the patients were with poor prognostic scores based on the International Extranodal Lymphoma Study Group (IELSG) risk scoring system [30]. All patients had previously received high dose methotrexate as part of initial treatment and most patients were of refractory disease. Of the three relapsed patients, one patient entered study at second relapse. Twenty-seven cycles of $\mathrm{R}-\mathrm{B}(\mathrm{O}) \mathrm{AD}$ were administered, at a median of three cycles per patient, and vincristine was omitted in four patients. Four patients were treated with initial dosage reductions in bendamustine and cytarabine by $25 \%$, due to elderly age ( $>70$ years; one patient 78 years of age received cytarabine $500 \mathrm{mg} / \mathrm{m}^{2}$ ). Chemotherapy was delayed in five of the 27 cycles but further dose reduction was not required as no subsequent cycle was postponed longer than 7 days. G-CFS was given to all patients. Patient characteristics and responses are summarized in Table 1.

\section{Efficacy and safety}

The ORR of $\mathrm{R}-\mathrm{B}(\mathrm{O}) \mathrm{AD}$ was $50 \%$ (95\% CI, 0.24 to 0.76 ), one patient achieving CR (10\%) and four PR (40\%). The CR patient showed lymphomatous infiltration in the left optic nerve with thickening visible on MRI that completely resolved after the second cycle of R-BAD. All subjects who progressed on salvage therapy were patients of refractory disease. One of these patients showed near complete resolution of multiple tumor sites during interim analysis (Fig. 1), however developed new lesions after the third cycle of therapy. Four of the five patients who progressed during study treatment received WBRT post salvage therapy. Primary toxicity of the combination regimen was reversible myelosuppression, mostly grade 3 or 4 neutropenia ( $89 \%$ of cycles). Grade 3 febrile neutropenia was observed in 33\%, grade 3 or 4 thrombocytopenia in $85 \%$, and grade 1 or 2 anemia in $70 \%$ of treatment cycles. The most common non-hematological toxicities were nausea and diarrhea, 30 and $19 \%$, respectively, mostly grade 1 or 2 . Infection (mostly pneumonia) was observed in three patients, all requiring antibiotic therapy, and one resulted in treatment related mortality. This was a 73 year old patient who received four cycles of R-BAD therapy with documented partial reduction in tumor after cycle two, and during cycle four developed urinary catheter related Klebsiella pneumoniae infection and progressive bronchopneumonia on chest imaging, with delayed hematologic recovery.

\section{Pharmacokinetic exposure data}

A total of 28 plasma and 16 CSF samples were collected. Time of maximum concentration $\left(t_{\max }\right)$ was found at the end of infusion ( $t_{\text {max,plasma }}=1 \mathrm{~h}$ ) for plasma and at $0.5 \mathrm{~h}$ after end of infusion $\left(t_{\max , \text { csf }}=1.5 \mathrm{~h}\right)$ for CSF. The $C_{\max }$ mean for plasma was $2669 \mathrm{ng} / \mathrm{mL}$ (SD $\pm 1176 \mathrm{ng} / \mathrm{mL}$ )

Table 1 Patient characteristics $(N=10)$ and responses

\begin{tabular}{|c|c|c|c|c|c|c|c|c|c|}
\hline $\begin{array}{l}\text { Patient } \\
\text { ID No. }\end{array}$ & $\begin{array}{l}\text { Sex/ } \\
\text { Age } \\
\text { (years) }\end{array}$ & $\begin{array}{l}\text { ECOG } \\
\text { PS }\end{array}$ & $\begin{array}{l}\text { IELSG } \\
\text { score }^{*}\end{array}$ & $\begin{array}{l}\text { Disease } \\
\text { state }\end{array}$ & $\begin{array}{l}\text { Previous } \\
\text { therapy }\end{array}$ & Tumor location & $\begin{array}{l}\text { R-B(O)AD cycles } \\
\text { completed }\end{array}$ & $\begin{array}{l}\text { Final } \\
\text { response }\end{array}$ & $\begin{array}{l}\text { PFS/OS } \\
\text { (months) }\end{array}$ \\
\hline 1 & $F / 68$ & 2 & 5 & Ref & $\begin{array}{l}\text { HDMTX+ } \\
\text { AraC }\end{array}$ & $\begin{array}{l}\text { D; periventricular, basal } \\
\text { ganglia }\end{array}$ & 3 & PD & $1.8 / 7.3$ \\
\hline 2 & $F / 55$ & 2 & 4 & Ref & $\begin{array}{l}\text { HDMTX+ } \\
\text { AraC }\end{array}$ & $\begin{array}{l}\text { D; periventricular, corpus } \\
\text { callosum }\end{array}$ & 2 & PD & $2.5 / 6.8$ \\
\hline 3 & M/75 & 1 & 4 & Rel & $\begin{array}{l}\text { HDMTX + } \\
\text { WBRT; } \\
\text { MPV-A }\end{array}$ & ND; L optic nerve & 4 & $C R$ & $21.7 />21.7$ \\
\hline 4 & $M / 42$ & 2 & 3 & Ref & HDMTX & D; basal ganglia & 2 & PD & $1.6 / 9.1$ \\
\hline 5 & $\mathrm{M} / 78$ & 2 & 3 & Rel & $\begin{array}{l}\text { HDMTX+ } \\
\text { AraC }\end{array}$ & ND; L parietal & 4 & PR & $6.9 />6.9$ \\
\hline 6 & $F / 55$ & 2 & 4 & Ref & $\begin{array}{l}\text { HDMTX+ } \\
\text { AraC }\end{array}$ & $N D ; L$ frontal, $R$ temporal & 3 & PD & $2.8 / 3.3$ \\
\hline 7 & $\mathrm{~F} / 47$ & 1 & 2 & Ref & $\begin{array}{l}\text { HDMTX+ } \\
\text { AraC }\end{array}$ & $D^{\mathbf{t}} ; \mathrm{L}$ frontal, periventricular & 1 & $P R$ & $2.8 / 2.8$ \\
\hline 8 & $F / 73$ & 2 & 5 & Rel & $\begin{array}{l}\text { HDMTX+ } \\
\text { AraC }\end{array}$ & $N D ; L$ frontal & 4 & PR & $4.4 / 4.4$ \\
\hline 9 & M/75 & 2 & 4 & Ref & $\begin{array}{l}\text { HDMTX+ } \\
\text { AraC }\end{array}$ & $N D^{t_{i}} ; L$ frontal & 2 & SD & $4.2 />4.2$ \\
\hline 10 & M/65 & 2 & 5 & Ref & HDMTX & $D^{\mathbf{t}} ; \mathrm{L}$ frontal, basal ganglia & 2 & PR & $3.9 / 3.9$ \\
\hline
\end{tabular}

Abbreviations: M, male; F, female; PS, performance status; Rel, relapsed; Ref, refractory; HDMTX, high dose methotrexate; AraC, cytarabine; WBRT, whole brain radiotherapy; MPV-A, methotrexate, vincristine, procarbazine, cytarabine; $D$, deep; ND, non-deep; L, left; R, right; CR, complete response; PR, partial response; SD, stable disease; PD, progressive disease; PFS, progression free survival; OS, overall survival

*IELSG risk = intermediate (IELSG score 2-3), high (IELSG score 4-5)

${ }^{t}$ Patients with leptomeningeal involvement in recurrent disease 

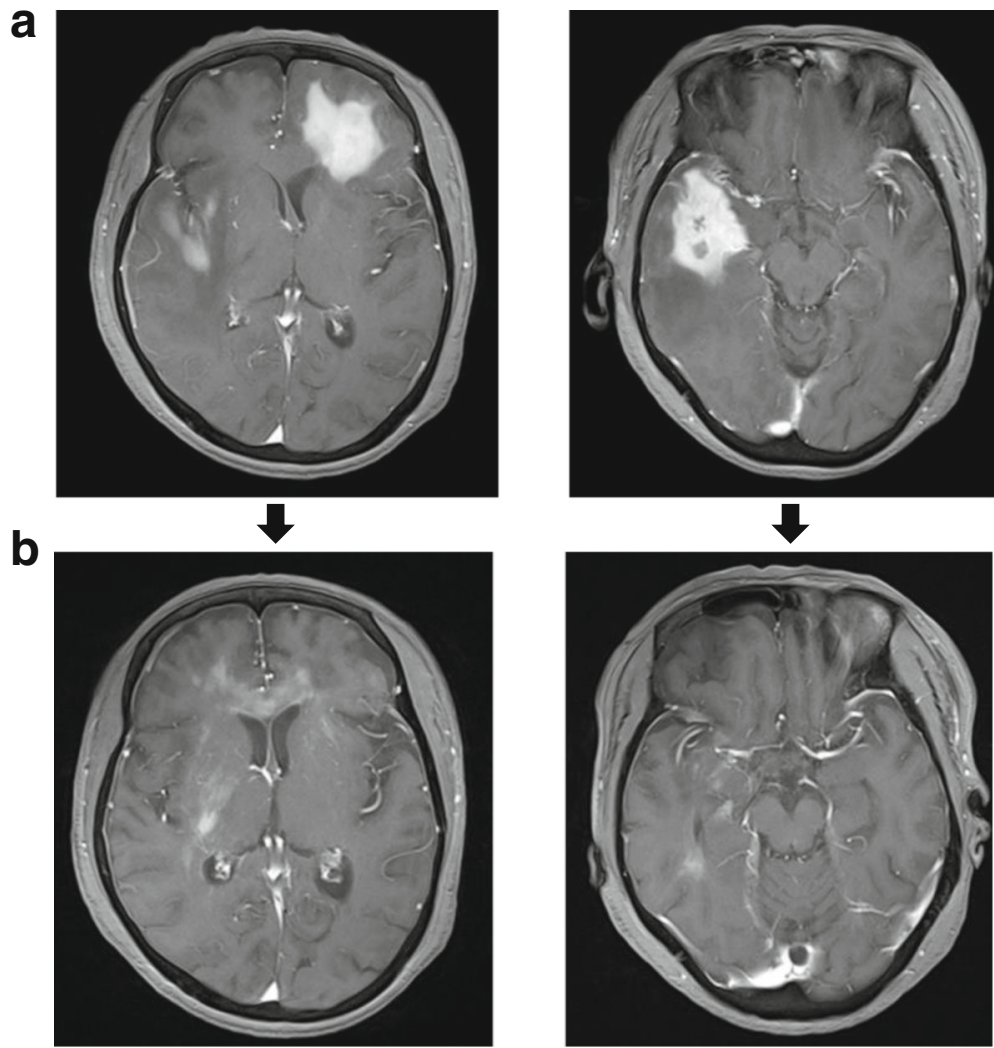

Fig. 1 Resolution of multi-focal (left frontal and right temporal lobe) disease in a 65 year old patient (ID No. 6) a) before and b) after two cycles of R-BOAD at interim analysis

and for CSF $0.397 \mathrm{ng} / \mathrm{mL}$ (SD $\pm 0.160 \mathrm{ng} / \mathrm{mL}$ ). CSF/ plasma exposure ratios were calculated to be 0.015 and $0.025 \%$ for $C_{\max }$ and $\mathrm{AUC}_{0 \text {-inf, respectively. Individual }}$ observations at $\mathrm{C}_{\max \text {,plasma }}$ and $\mathrm{C}_{\max \text {,csf }}$ were available for eight patients. All patients who showed an interim response were subjects with involvement of non-deep structures as classified by Ferreri et al. [30] and those displaying tumor regression at deep sites possessed higher trends in $\mathrm{C}_{\text {max,plasma }}$ and $\mathrm{C}_{\text {max,csf }}$ values (Fig. 2).

\section{Population pharmacokinetic model}

Pharmacokinetic data was best fit by a four-compartment model incorporating two plasma compartments (central and peripheral) with drug distributing from central plasma into an intermediate biophase reservoir and then into a final CSF compartment, with first-order elimination of drug from both central plasma and CSF compartments (Fig. 3). The biophase compartment was required to account for the delay in time to reach maximum drug concentrations in the CSF after infusion completion, compared to the immediate peak in plasma achieved at the end of IV infusion. The overall volume of distribution in plasma $\left(\mathrm{V}_{\text {plasma }}=\mathrm{V}_{1}+\mathrm{V}_{2}\right.$ $=19.7 \mathrm{~L})$ was similar to previously reported values $(\sim 20 \mathrm{~L})$ as was elimination clearance from the central plasma compartment $(32.5 \mathrm{~L} / \mathrm{hr}$. for patient with $\mathrm{BSA}=1.675)[26$, 27]. Inter-individual variability in pharmacokinetic variables was moderate, with coefficient of variance values near $40 \%$. A proportional model was employed to assess residual variability for which CV\% was $17 \%$. Overall, observed bendamustine concentrations in plasma and CSF were adequately fit by population predicted median values, indicating ability of the final model to describe central tendencies (Fig. 4). Estimates for the final model were similar to bootstrap replicates and were contained within the $90 \% \mathrm{CI}$, representing absence of significant bias. The PK parameter mean estimates with associated standard errors and the $90 \%$ bootstrap confidence intervals are presented in Table 2.

\section{Discussion}

This was a prospective pilot trial investigating a bendamustine-based combination regimen in patients with R/R primary CNS lymphoma. Recurrent disease is difficult to treat in that progression is usually rapid and aggressive leading to significant impairment in performance status and neurological deterioration, a limited number of salvage strategies exist, and survival outcomes are suboptimal despite additional therapy. The 50\% ORR of the study regimen falls within the range of efficacy 

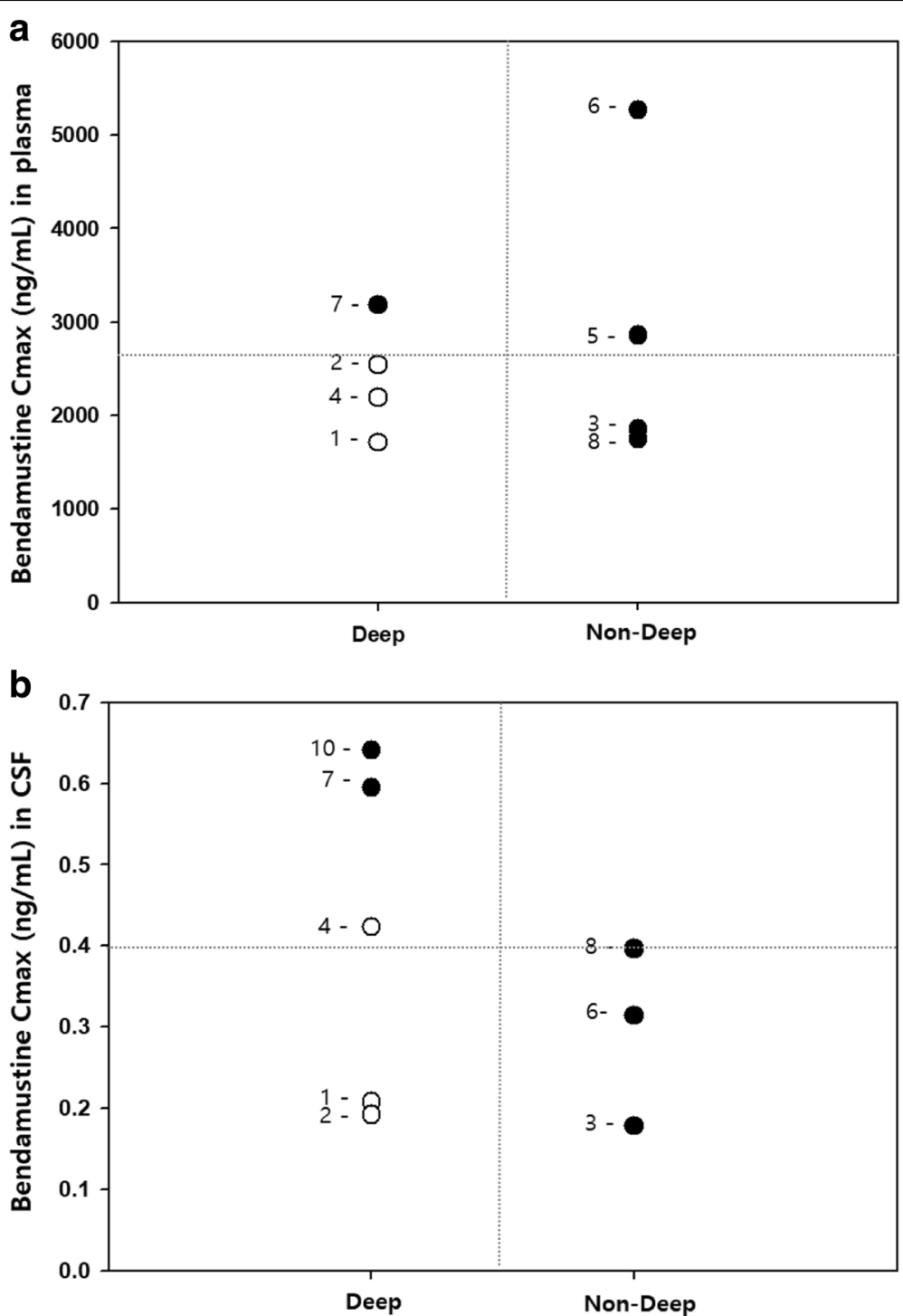

Fig. 2 Relationship between interim response status and a) plasma $C_{\max }$ and $\left.\mathbf{b}\right)$ CSF $C_{\max }$ bendamustine concentrations, and tumor location. Deep structures include periventricular regions, basal ganglia, brainstem, and cerebellum regions. Closed circles $(\cdot)$ represent responders and open circles $\left(^{\circ}\right)$ non-responders. Patient identification numbers are notated and the dashed line depicts mean $C_{\max }$ values for plasma and CSF. Bendamustine exposure was not significantly higher for the patient resulting in treatement related death (ID No. 8)

prospectively observed with current salvage regimens utilized in R/R PCNSL. A previous case series report demonstrated a best response rate of $50 \%$ to single agent bendamustine therapy with acceptable toxicity but was retrospective in nature and showed a relatively short lived response. In this study, utilization of mechanistically augmenting chemotherapeutic agents resulted in an active salvage regimen with remarkable effects observed on imaging in patients showing response. Such activity may largely be attributed to the anticipated synergy effect of combination bendamustine and cytarabine, considering the majority of the patients had progressed despite previous treatment with cytarabine as a part of induction therapy.
However, such synergistic effects of the combination also lead to significant marrow suppression, and hematologic toxicity observed with $\mathrm{R}-\mathrm{B}(\mathrm{O}) \mathrm{AD}$ was considerable with grade 3 or 4 neutropenia and thrombocytopenia experienced in $>85 \%$ of treatment cycles. The rate of toxicity observed was somewhat higher than that reported in a previous study investigating treatment of mantle-cell non-Hodgkin lymphoma patients with bendamustine $\left(70 \mathrm{mg} / \mathrm{m}^{2}\right)$ and cytarabine $\left(800 \mathrm{mg} / \mathrm{m}^{2}\right)$ combination therapy [14], and may be explained by ethnic and disease differences in the study population. Severe infection was observed in three patients, all with involvement of the lungs, one patient with underlying COPD disease and another with a history of fungal pneumonia. Due to 


\section{IV infusion (1 h)}

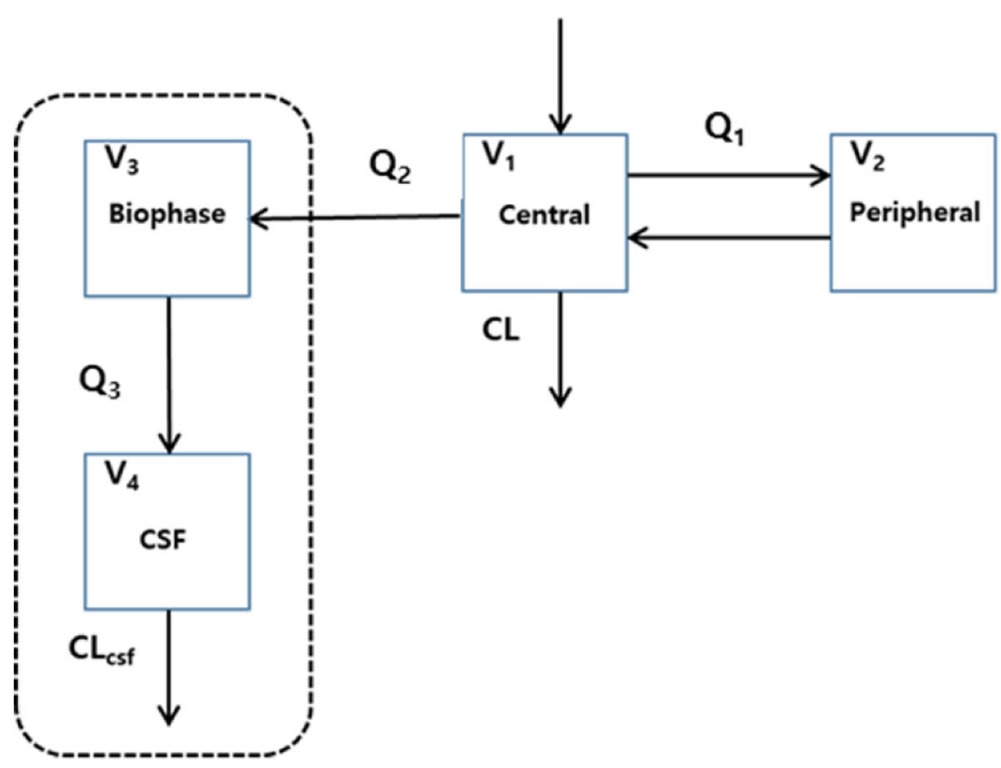

Fig. 3 Schematics of structural model used for bendamustine. Abbreviations: $V$, volume of distribution; $Q$, inter-compartmental clearance; $C L$, clearance of central plasma compartment; $\mathrm{CL}_{\mathrm{cs}}$, clearance of CSF compartment

significant myelosuppression despite the use of prophylactic growth factor support, study protocol was later amended with reduction in cytarabine dosage to $500 \mathrm{mg} / \mathrm{m}^{2}$ and stricter criteria for dose adjustments in the case of severe cytopenias.

To our knowledge, this is the first study to characterize the pharmacokinetics of bendamustine in human CSF. Given multiple sampling of the CSF through lumbar puncture is not feasible for both medical and ethical reasons, a sparse sampling method and population PK approach was employed with collection of CSF at different time points among patients. CSF concentrations of bendamustine were minimal compared to plasma values with an AUC exposure ratio of $0.025 \%$. Although absolute values of CSF drug levels were much lower than those in plasma, higher trends in maximum peak concentrations of drug in

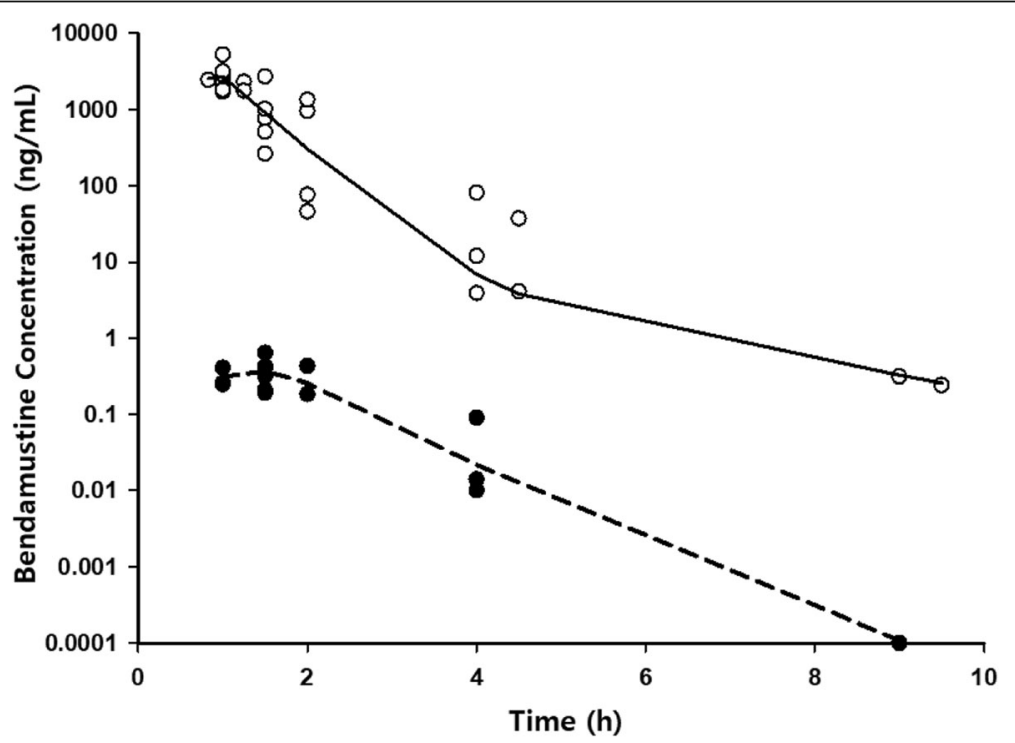

Fig. 4 Bendamustine concentration-time profiles. Circles represent observed values for plasma $(\cdot)$ and $\operatorname{CSF}\left({ }^{\circ}\right)$ drug levels. Best-fit curves from the final population PK model are shown for plasma () and CSF (--) 
Table 2 Population PK model parameter estimates and nonparametric bootstrap 90\% confidence intervals

\begin{tabular}{|c|c|c|c|c|c|}
\hline \multirow[t]{2}{*}{ Parameter } & \multirow[t]{2}{*}{ Estimate } & \multirow{2}{*}{$\begin{array}{l}\text { RSE } \\
(\%) \\
\text { /CV } \\
(\%)\end{array}$} & \multicolumn{3}{|c|}{ Bootstrap Replicates } \\
\hline & & & Median & $\mathrm{Cl}(90 \%)$ & \\
\hline$\overline{V_{1}}$ & 14.9 & 19.2 & 14.1 & 4.9 & 20.7 \\
\hline$C L$ & 32.5 & 10.5 & 31.4 & 23.9 & 39.2 \\
\hline$V_{2}$ & 0.508 & 14.4 & 0.455 & 0.186 & 0.846 \\
\hline $\mathrm{Q}_{1}$ & 0.238 & 15.3 & 0.205 & 0.041 & 0.660 \\
\hline$V_{3}$ & 0.323 & 9.8 & 0.322 & 0.186 & 0.442 \\
\hline $\mathrm{Q}_{2}$ & 0.569 & 15.8 & 0.569 & 0.344 & 0.836 \\
\hline$V_{4}$ & 0.032 & 40.9 & 0.032 & 0.014 & 0.041 \\
\hline $\mathrm{Q}_{3}$ & 0.793 & 16.8 & 0.795 & 0.573 & 1.360 \\
\hline $\mathrm{CL}_{\mathrm{csf}}$ & 0.075 & 43.5 & 0.075 & 0.059 & 0.140 \\
\hline$I I V V_{1}$ & 0.230 & 42.9 & 0.220 & 0.011 & 0.480 \\
\hline IIV CL & 0.089 & 39.9 & 0.086 & 0.014 & 0.190 \\
\hline RV & 0.420 & 17.4 & 0.390 & 0.210 & 0.620 \\
\hline
\end{tabular}

Abbreviations: RSE (\%, for structural parameter estimates), relative standard error; $\mathrm{CV}(\%$, for IIV), coefficient of variance; $\mathrm{Cl}$, confidence interval; $\mathrm{V}(\mathrm{L})$, volume of distribution; $C L(L / h)$, elimination clearance; $Q(L / h)$, inter-compartmental clearance; CLcsf (L/h), CSF compartment clearance; IIV, inter-individual variability; $\mathrm{RV}$, residual variability

the CSF showed correlation to tumor response, particularly in patients with lymphoma involvement of deep brain structures. Among patients with observations sampled at $t_{\text {max,plasma }}$ and $t_{\text {max,csf }}$, all subjects with tumors outside deep regions showed significant tumor regression regardless of PK concentrations. This is in line with the IELSG scoring system in which disease involvement of deep structures is an independent prognostic variable associated with poor survival [30].

The inclusion of a biophase reservoir between the central plasma and CSF compartment allowed for the observed delay in time to peak concentrations of the CSF, and may be representative of anatomical structures that are part of the CSF macrocirculation but are farther from the sampled lumbar puncture site. The concentration time profile of the biophase reservoir was simulated using the population PK model and drug exposure was predicted to be similar to that of the CSF compartment (Additional file 1: Figure S1). Clearance of bendamustine from the CSF compartment was rapid with an elimination half-life $t_{1 / 2}, \quad$ csf $=0.30 \mathrm{~h}$ calculated from model parameter estimates. Bendamustine like other nitrogen mustards has limited stability and undergoes degradation by hydrolysis, which increases in the presence of water and higher temperatures [31, 32]. Such chemical properties of bendamustine may contribute to the extensive elimination of drug observed in the CSF.

A previous tissue distribution study of IV ${ }^{14} \mathrm{C}$-bendamustine demonstrated radioactivity in brain tissue of mice, rats, and dogs, suggesting permeability of drug through the blood brain barrier (BBB) [33]. Despite the association observed between bendamustine concentrations in the CSF and drug activity, it is doubtful that such low concentrations found in our study are representative of true drug levels in the brain parenchyma. This may partially be explained by differences in drug penetration through the $\mathrm{BBB}$ and the blood-CSF barrier due to variations in the endothelium and transporter expression, in which case CSF concentrations would not serve as an adequate marker of drug delivery to the tumor location. Such discrepancies between drug levels in the CSF and brain tissue have been reported for several chemotherapeutic agents. Temsirolimus, an mTOR inhibitor, has demonstrated drug levels in tissue above those in the plasma of glioma patients, yet in another study negligible CSF drug levels were observed in CNS lymphoma patients [34, 35]. Single agent rituximab therapy has shown clinical activity in disease of the CNS but also possesses poor detectable drug levels in the CSF after IV administration [20]. Therapeutic levels of such drugs in the brain parenchyma are thought to be achieved by penetration of a $\mathrm{BBB}$ that is with compromised integrity due to the highly disordered and permeable vasculature of the infiltrating tumor [36]. In these settings drug concentrations are expected to decrease with increasing distance from the tumor bulk.

\section{Conclusion}

A relatively high proportion of patients with PCNSL will experience progression of disease, yet the number of prospective trials on salvage therapy remains small due to the rarity of disease and rapidly progressive nature. It is accepted that salvage therapy is beneficial and significantly improves survival in comparison to palliative care. Although this study reports data from a limited number of patients, it supports the use of a bendamustine-based combination regimen as an option for salvage therapy, especially in patients who are no longer chemo-sensitive to methotrexate or those who have developed cumulative renal or neurotoxicity from treatment. Hematologic toxicity of the regimen is significant but manageable with dose reduction and supportive care. A lower dosage of cytarabine at $500 \mathrm{mg} / \mathrm{m}^{2}$ may be more feasible to avoid prolongation of significant marrow suppression and will be investigated in a Phase II study. Evaluation of plasma and CSF data with development of a population PK model shows CSF drug levels are low with rapid decline and are unlikely to be an accurate predictor of drug concentrations at the tumor site, thus should not be utilized as a surrogate of CNS drug delivery. However, trends in higher peak bendamustine concentrations in 
both plasma and CSF were observed for patients who showed response to treatment in deep tumor locations.

\section{Additional file}

Additional file 1: Figure S1. Simulations of bendamustine concentrationtime profiles for compartments included in final PK model. C1, central plasma compartment; C2, peripheral plasma compartment; C3, biophase compartment; C4, CSF compartment. (DOCX 53 kb)

\section{Abbreviations}

AraC: Cytarabine; Cl: Confidence interval; CL: Clearance of central plasma compartment; CLCsf: Clearance of CSF compartment; CR: Complete response; CSF: Cerebrospinal fluid; CV: Coefficient of variance; D: Deep; DLBCL: Diffuse large B-cell lymphoma; F: Female; HDMTX: High dose methotrexate; IELSG: International Extranodal Lymphoma Study Group; IIV: Inter-individual variability; L: Left; M: Male; MPV-A: Methotrexate, vincristine, procarbazine, cytarabine; ND: Non-deep; ORR: Overall response rate; OS: Overall survival; PCNSL: Primary central nervous system lymphoma; PD: Progressive disease; PFS: Progression free survival; PK: Pharmacokinetics; PR: Partial response PS: Performance status; Q: Inter-compartmental clearance; R: Right; R/ R: Relapsed/refractory; Ref: Refractory; Rel: Relapsed; RSE: Relative standard error; RV: Residual variability; SD: Stable disease; V: Volume of distribution; WBRT: Whole brain radiotherapy

\section{Availability of data and materials}

The dataset used and analyzed during the current study is available from the corresponding author on reasonable request.

\section{Funding}

This study was supported by a grant (HCRI 16915-1) provided from Chonnam National University Hwasun Hospital Institute for Biomedical Science. The funding body had no role in designing of the study, experimental analyses, or manuscript production.

\section{Authors' contributions}

TK, HY, and DY contributed to the design and conceptualization of the study, collection and interpretation of data, and drafting and revising of the manuscript. $\mathrm{HC}, \mathrm{HL}, \mathrm{SJ}$, and $\mathrm{JA}$ contributed to the collection and interpretation of data and revising of the manuscript. $H K$ and $J \mathrm{~L}$ contributed to data analyses and editing of the manuscript. All authors have read and approved the final manuscript.

\section{Ethics approval and consent to participate}

Study protocol was approved by the institutional ethics committee at Chonnam National University Hwasun Hospital (CNUHH-2016-145) and conducted in accordance to the Declaration of Helsinki principles. All patients provided written informed consent.

\section{Consent for publication}

Written informed consent for publication of clinical details, outcomes, and images was obtained from all patients. A copy of the consent form is available for review by the Editor of this journal.

\section{Competing interests}

The authors declare that they have no competing interests.

\section{Publisher's Note}

Springer Nature remains neutral with regard to jurisdictional claims in published maps and institutional affiliations.

\section{Author details}

${ }^{1}$ College of Pharmacy and Research Institute of Pharmaceutical Sciences, Seoul National University, 1 Gwanakro, Gwanakgu, Seoul 08826, Republic of Korea. ${ }^{2}$ Research Center for Cancer Immunotherapy, Chonnam National University Hwasun Hospital, 322 Seoyangro, Hwasun, Jeollanamdo 58128, Republic of Korea. ${ }^{3}$ Department of Hematology-Oncology, Chonnam National University Hwasun Hospital, 322 Seoyangro, Hwasun, Jeollanamdo
58128, Republic of Korea. ${ }^{4}$ Department of Biostatistics and Bioinformatics, Pharma Partnering Inc., 74 Olympicro, Songpagu, Seoul 05556, Republic of Korea.

Received: 17 January 2018 Accepted: 25 June 2018

Published online: 09 July 2018

\section{References}

1. Villano JL, Koshy M, Shaikh H, Dolecek TA, McCarthy BJ. Age, gender, and racial differences in incidence and survival in primary CNS lymphoma. Br J Cancer. 2011;105(9):1414-8.

2. Dolecek TA, Propp JM, Stroup NE, Kruchko C. CBTRUS statistical report: primary brain and central nervous system tumors diagnosed in the United States in 2005-2009. Neuro-Oncology. 2012;14(Suppl 5):v1-49.

3. Hoang-Xuan $\mathrm{K}$, Bessell $\mathrm{E}$, Bromberg J, Hottinger AF, Preusser M, Ruda R, Schlegel U, Siegal T, Soussain C, Abacioglu U, et al. Diagnosis and treatment of primary CNS lymphoma in immunocompetent patients: guidelines from the European Association for Neuro-Oncology. Lancet Oncol. 2015;16(7):e322-32.

4. Jahnke K, Thiel E, Martus P, Herrlinger U, Weller M, Fischer L, Korfel A. Relapse of primary central nervous system lymphoma: clinical features, outcome and prognostic factors. J Neuro-Oncol. 2006;80(2):159-65.

5. Plotkin SR, Betensky RA, Hochberg FH, Grossman SA, Lesser GJ, Nabors LB, Chon B, Batchelor TT. Treatment of relapsed central nervous system lymphoma with high-dose methotrexate. Clin Cancer Res. 2004:10(17):5643-6.

6. Pentsova E, Deangelis LM, Omuro A. Methotrexate re-challenge for recurrent primary central nervous system lymphoma. J Neuro-Oncol. 2014;117(1):161-5.

7. Yamanaka R. Management of refractory or relapsed primary central nervous system lymphoma (review). Mol Med Rep. 2009;2(6):879-85.

8. Phillips EH, Fox CP, Cwynarski K. Primary CNS lymphoma. Curr Hematol Malig Rep. 2014;9(3):243-53.

9. Grommes C, DeAngelis LM. Primary CNS lymphoma. J Clin Oncol. 2017;35(21):2410-8.

10. Dubbelman AC, Jansen RS, Rosing H, Darwish M, Hellriegel E, Robertson P $J r$, Schellens $J H$, Beijnen $J H$. Metabolite profiling of bendamustine in urine of cancer patients after administration of [14C]bendamustine. Drug Metab Dispos. 2012;40(7):1297-307.

11. Renfrow JJ, Detroye A, Chan M, Tatter S, Ellis T, McMullen K, Johnson A, Mott R, Lesser GJ. Initial experience with bendamustine in patients with recurrent primary central nervous system lymphoma: a case report. J Neuro-Oncol. 2012;107(3):659-63.

12. Chamberlain MC. Salvage therapy with bendamustine for methotrexate refractory recurrent primary CNS lymphoma: a retrospective case series. J Neuro-Oncol. 2014;118(1):155-62.

13. Castegnaro S, Visco C, Chieregato K, Bernardi M, Albiero E, Zanon C, Madeo D, Rodeghiero F. Cytosine arabinoside potentiates the apoptotic effect of bendamustine on several B- and T-cell leukemia/lymphoma cells and cell lines. Leuk Lymphoma. 2012;53(11):2262-8.

14. Visco C, Finotto S, Zambello R, Paolini R, Menin A, Zanotti R, Zaja F, Semenzato G, Pizzolo G, D'Amore ES, et al. Combination of rituximab, bendamustine, and cytarabine for patients with mantle-cell non-Hodgkin lymphoma ineligible for intensive regimens or autologous transplantation. J Clin Oncol. 2013;31(11):1442-9.

15. Visco C, Chiappella A, Nassi L, Patti C, Ferrero S, Barbero D, Evangelista A, Spina M, Molinari A, Rigacci L, et al. Rituximab, bendamustine, and low-dose cytarabine as induction therapy in elderly patients with mantle cell lymphoma: a multicentre, phase 2 trial from Fondazione Italiana Linfomi. Lancet Haematol. 2017:4(1):e15-23.

16. Hiraoka N, Kikuchi J, Yamauchi T, Koyama D, Wada T, Uesawa M, Akutsu M, Mori S, Nakamura Y, Ueda T, et al. Purine analog-like properties of bendamustine underlie rapid activation of DNA damage response and synergistic effects with pyrimidine analogues in lymphoid malignancies. PLoS One. 2014;9(3):e90675.

17. Herold M, Schulze A, Niederwieser D, Franke A, Fricke HJ, Richter P, Freund $M$, Ismer B, Dachselt $K$, Boewer $C$, et al. Bendamustine, vincristine and prednisone (BOP) versus cyclophosphamide, vincristine and prednisone (COP) in advanced indolent non-Hodgkin's lymphoma and mantle cell lymphoma: results of a randomised phase III trial (OSHO\# 19). J Cancer Res Clin Oncol. 2006:132(2):105-12.

18. Song $Y$, Wen $Y$, Xue $W$, Zhang $Y$, Zhang $M$. Effect of rituximab on primary central nervous system lymphoma: a meta-analysis. Int J Hematol. 2017;106(5):612-21. 
19. Nayak L, Abrey LE, Drappatz J, Gilbert MR, Reardon DA, Wen PY, Prados M, Deangelis LM, Omuro A. Multicenter phase II study of rituximab and temozolomide in recurrent primary central nervous system lymphoma. Leuk Lymphoma. 2013;54(1):58-61.

20. Batchelor TT, Grossman SA, Mikkelsen T, Ye X, Desideri S, Lesser GJ. Rituximab monotherapy for patients with recurrent primary CNS lymphoma. Neurology. 2011;76(10):929-30.

21. Eichbaum MH, Schuetz F, Khbeis T, Lauschner I, Foerster F, Sohn C, Schneeweiss A. Weekly administration of bendamustine as salvage therapy in metastatic breast cancer: final results of a phase II study. Anti-Cancer Drugs. 2007;18(8):963-8.

22. Chamberlain MC, Johnston SK. Salvage therapy with single agent bendamustine for recurrent glioblastoma. J Neuro-Oncol. 2011;105(3):523-30.

23. Chamberlain MC, Colman H, Kim BT, Raizer J. Salvage therapy with bendamustine for temozolomide refractory recurrent anaplastic gliomas: a prospective phase II trial. J Neuro-Oncol. 2017;131(3):507-16.

24. Abrey LE, Batchelor TT, Ferreri AJ, Gospodarowicz M, Pulczynski EJ, Zucca E, Smith JR, Korfel A, Soussain C, DeAngelis LM, et al. Report of an international workshop to standardize baseline evaluation and response criteria for primary CNS lymphoma. J Clin Oncol. 2005;23(22):5034-43.

25. Tang NS, Li HQ, Tang ML, Li J. Confidence interval construction for the difference between two correlated proportions with missing observations. J Biopharm Stat. 2016;26(2):323-38.

26. Owen JS, Melhem M, Passarell JA, D'Andrea D, Darwish M, Kahl B. Bendamustine pharmacokinetic profile and exposure-response relationships in patients with indolent non-Hodgkin's lymphoma. Cancer Chemother Pharmacol. 2010;66(6):1039-49.

27. Dubbelman AC, Rosing H, Darwish M, D'Andrea D, Bond M, Hellriegel E, Robertson P Jr, Beijnen JH, Schellens JH. Pharmacokinetics and excretion of 14C-bendamustine in patients with relapsed or refractory malignancy. Drugs R D. 2013;13(1):17-28.

28. Dubbelman AC, Tibben M, Rosing H, Gebretensae A, Nan L, Gorman SH, Robertson P Jr, Schellens JH, Beijnen JH. Development and validation of LCMS/MS assays for the quantification of bendamustine and its metabolites in human plasma and urine. J Chromatogr B Analyt Technol Biomed Life Sci. 2012;893-894:92-100.

29. Hooker AC, Staatz CE, Karlsson MO. Conditional weighted residuals (CWRES): a model diagnostic for the FOCE method. Pharm Res. 2007;24(12):2187-97.

30. Ferreri AJ, Blay JY, Reni M, Pasini F, Spina M, Ambrosetti A, Calderoni A, Rossi A, Vavassori V, Conconi A, et al. Prognostic scoring system for primary CNS lymphomas: the international Extranodal lymphoma study group experience. J Clin Oncol. 2003;21(2):266-72.

31. Teichert J, Baumann F, Chao Q, Franklin C, Bailey B, Hennig L, Caca K, Schoppmeyer K, Patzak U, Preiss R. Characterization of two phase I metabolites of bendamustine in human liver microsomes and in cancer patients treated with bendamustine hydrochloride. Cancer Chemother Pharmacol. 2007:59(6):759-70.

32. Kasa S, Raja Sekhar Reddy M, Kadaboina RS, Murki V, Mulukutla VS. Stabilityindicating $\mathrm{LC}$ method for the estimation of bendamustine hydrochloride and its related impurities. J Chromatogr Sci. 2014;52(7):573-83.

33. Cheson BD, Rummel MJ. Bendamustine: rebirth of an old drug. J Clin Oncol. 2009;27(9):1492-501.

34. Kuhn JG, Chang SM, Wen PY, Cloughesy TF, Greenberg H, Schiff D, Conrad C, Fink KL, Robins HI, Mehta $\mathrm{M}$, et al. Pharmacokinetic and tumor distribution characteristics of temsirolimus in patients with recurrent malignant glioma. Clin Cancer Res. 2007;13(24):7401-6.

35. Korfel A, Schlegel U, Herrlinger U, Dreyling M, Schmidt C, von Baumgarten L, Pezzutto A, Grobosch T, Kebir S, Thiel E, et al. Phase II trial of Temsirolimus for relapsed/refractory primary CNS lymphoma. J Clin Oncol. 2016;34(15):1757-63.

36. Muldoon LL, Soussain C, Jahnke K, Johanson C, Siegal T, Smith QR, Hall WA, Hynynen K, Senter PD, Peereboom DM, et al. Chemotherapy delivery issues in central nervous system malignancy: a reality check. J Clin Oncol. 2007;25(16):2295-305.

Ready to submit your research? Choose BMC and benefit from:

- fast, convenient online submission

- thorough peer review by experienced researchers in your field

- rapid publication on acceptance

- support for research data, including large and complex data types

- gold Open Access which fosters wider collaboration and increased citations

- maximum visibility for your research: over $100 \mathrm{M}$ website views per year

At BMC, research is always in progress.

Learn more biomedcentral.com/submissions 